\title{
BRASIL: ESTADO INTERVENCIONISTA OU LIBERAL?
}

\author{
BRAZIL: INTERVENTIONIST OR LIBERAL STATE?
}

\section{Átila de Alencar Araripe Magalhães ${ }^{1}$ Renata Albuquerque Lima ${ }^{2}$}

RESUMO: O presente artigo tem como escopo analisar o caminho que o Brasil percorreu, desde quando era colônia de Portugal, até o modelo econômico adotado atualmente, no contexto da Constituição Federal de 1988. Nesse sentido, verificarse-á se as políticas adotadas se inclinam para o liberalismo ou intervencionismo estatal. O estudo investiga, ainda, como as matérias-primas, a cana-de-açúcar e o café colocaram o Brasil em contato com o mercado internacional, no pré e no pósRepública. Em um crescendo, o trabalho contempla também algumas políticas econômicas adotadas por Getúlio Vargas, a partir da década de 1930, até os governos militares nos anos seguintes. Examinar-se-á, por conseguinte, as políticas adotadas pelos referidos governos militares, as quais fizeram com que o Brasil registrasse números positivos, em termos econômicos, o chamado milagre econômico. Por fim, será exposto como a vigente Constituição Brasileira, no pósredemocratização, tem desenhado o atual modelo econômico vigente. Utilizou-se, para tanto, o método teórico-bibliográfico, através de pesquisa bibliográfica e legal, sem olvidar artigos científicos que versam sobre os temas tratados. A abordagem do caso é inserida em uma pesquisa qualitativa, pois analisa a trajetória econômica brasileira liberal ou interventora, desde o Brasil-Colônia até a contemporaneidade.

\footnotetext{
${ }^{1}$ Pós-doutorando em Direito pela Universidade Federal de Santa Catarina - UFSC. Doutor em Direito Constitucional pela Universidade de Fortaleza - UNIFOR. Mestre em Administração de Empresas pela Universidade de Fortaleza - UNIFOR. Especialista em Direito e Processo Tributários pela Universidade de Fortaleza - UNIFOR e especialista em Direito Empresarial pela Universidade Estadual do Ceará - UECE. É professor de Direito Processual Civil da Universidade de Fortaleza - UNIFOR, na Cidade de Fortaleza/CE, Brasil. Advogado. E-mail: atila@leiteararipe.adv.br. ORCID: https://orcid.org/0000-0002-1964-4071

2 Pós-Doutora em Direito pela Universidade Federal de Santa Catarina. Doutora em Direito Constitucional pela Universidade de Fortaleza - UNIFOR. Atualmente professora do Mestrado em Direito e da Graduação em Direito da UNICHRISTUS. Professora-Adjunta do Curso de Direito da Universidade Estadual Vale do Acaraú - UVA. Coordenadora do Curso de Direito da Faculdade Luciano Feijão - FLF. Email: realbuquerque@yahoo.com.br. ORCID: https://orcid.org/0000-00024019-9558
} 
Palavras-chave: Economia; Estado interventor; Estado liberal.

ABSTRACT: The purpose of this article is to analyze the path that Brazil has undergone, from when it was a colony of Portugal, to the economic model adopted today, in the context of the Federal Constitution of 1988. In this sense, it will be verified if the policies adopted are inclined to liberalism or interventionism. The study also investigates how raw materials, sugar cane and coffee placed Brazil in contact with the international market, both pre and post-republic. In a crescendo, the work also contemplates some economic policies adopted by Getúlio Vargas, from the decade of 1930, until the military governments in the following years. It will therefore examine the policies adopted by the aforementioned military governments, which caused Brazil to record economic numbers, the so-called "economic miracle". Finally, it will be exposed how the current Brazilian Constitution, in postre-democratization, has designed the current brazilian economic model. For that, the theoretical-bibliographic method was used, through bibliographical and legal research, without forgetting scientific articles that deal with the topics discussed. The approach of the case is inserted in a qualitative research, since it analyzes the brazilian liberal or interventionist trajectory, from Brazil-Colony to contemporaneity.

Key-words: Economy; Interventor State; Liberal State.

Sumário: 1. Introdução; 2. Historiografia econômica brasileira: análise de algumas políticas públicas adotadas por gestores brasileiros; 2.1. O "milagre econômico" brasileiro; 3. Da vigente ordem econômica constitucional: influências e princípios; 3.1. Diretrizes econômicas da Constituição Federal de 1988; 3.2. Dos demais princípios regentes da economia brasileira à luz do texto constitucional; 4. Brasil: Estado liberal ou intervencionista; 5. Considerações Finais; 6. Referências.

\section{INTRODUÇÃO}

O estudo a seguir desenvolvido analisa a economia brasileira do período colonial, onde o Brasil era um grande exportador de matéria-prima e perpassa pelo momento em que se concentrou na produção de cana-de-açúcar e café, até a quebra da bolsa de Nova Iorque, em 1929, quando os produtores brasileiros amargaram prejuízos financeiros de grande monta. Vê-se que após essa crise econômica mundial, o mercado brasileiro se reinventa, graças às políticas intervencionistas de Getúlio Vargas, as quais passam a estimular a agricultura e a indústria têxtil que 
tomava forma no Brasil. Verifica-se ainda o alinhamento do Brasil com as grandes potências capitalistas da época, em especial com os Estados Unidos da América. Os investimentos estadunidenses aportam por aqui e são um dos fatores de alavancamento da economia local. Importantes instituições são criadas, a exemplo da Companhia Siderúrgica Nacional, em 1941, localizada na Cidade de Volta Redonda, Rio de Janeiro.

Com o fim da Segunda Grande Guerra, a intervenção do Brasil na economia aumenta e criam-se várias empresas estatais, que visavam a atender a indústria de base, como, por exemplo, a Companhia Vale do Rio Doce e a Eletrobrás. Essa postura intervencionista adotada na Era Vargas iria então refletir diretamente nos próximos Governos, em especial nos dos militares. Nessa nova fase da História brasileira, o parque industrial iniciado na Era Vargas é fortalecido. É criado o Plano de Ação Estratégica do Governo, que buscava equilibrar a inflação e a instabilidade do mercado à época. $\mathrm{O}$ intuito era estabilizar os preços, a inflação, o mercado e para isso foram realizadas e levantadas instituições que hoje regem o mercado interno, como o Banco Central e o Conselho Monetário Nacional.

Em um segundo momento, é criado o Plano de Ação Integrada do Governo, considerado o primeiro plano organizado voltado à condução economia. Dentre as ações, destacam-se o combate à inflação, conjuntamente com medidas que visavam reformar estruturalmente a economia, como a reforma tributária, a monetáriafinanceira e a política externa. $\mathrm{Na}$ área fiscal, os militares conseguem regular a arrecadação e diminuir de forma considerável o déficit fiscal. Por outro lado, há majoração de impostos. Com o aumento das receitas, o país ganha fôlego para fazer investimentos públicos. Verifica-se também maior rigidez no controle dos gastos e dos financiamentos públicos; incentivam-se as exportações, os investimentos estrangeiros e o mercado de capitais. Essa foi a receita do chamado "milagre econômico", era de ouro em que o Brasil foi elevado à categoria de potência econômica mundial. 
Em relação ao cerne desse trabalho, o que se buscou foi investigar se os governos brasileiros adotaram, ao longo da historiografia econômica do Brasil, políticas intervencionistas ou liberais. Para tanto, algumas políticas econômicas adotadas no Brasil-Colônia, no Brasil-Império e no Brasil-República foram estudadas, culminando com o estudo da Constituição Federal de 1988 e da recém publicada Medida Provisória $n^{\circ} 881$, de 30 de abril de 2019, a qual "Institui a Declaração de Direitos de Liberdade Econômica, estabelece garantias de livre mercado, análise de impacto regulatório, e dá outras providências."

Em especial, foram analisado princípios como liberdade de iniciativa (arts. $1^{\circ}$, IV e 170), propriedade privada (art. 170, II), liberdade de trabalho, ofício ou profissão (art. $5^{\circ}, \mathrm{XIII}$ ), garantia do direito de propriedade (art. $5^{\circ}, \mathrm{XXII}$ ) e livre concorrência (art. 170, IV), em cotejo com as gestões públicas. Para se alcançar o fim almejado, foi utilizado o método teórico-bibliográfico, através de pesquisa bibliográfica e legal, sem olvidar artigos científicos que versam sobre os temas tratados. A abordagem do caso é inserida em uma pesquisa qualitativa, pois analisa a trajetória econômica brasileira liberal ou intervencionista, desde o Brasil-Colônia até a contemporaneidade.

\section{HISTORIOGRAFIA ECONÔMICA BRASILEIRA: ANÁLISE DE} ALGUMAS POLÍTICAS PÚBLICAS ADOTADAS POR GESTORES BRASILEIROS

A negociação data dos primórdios da Humanidade. Muito antes da Revolução Industrial eclodir, o homem da Roma Antiga e da Idade Média, de uma forma geral, desenvolvera técnicas mercantilistas. E foi graças a isso que as navegações foram impulsionadas, e que os europeus conseguiram descobrir novas terras, impulsionados pelo espírito comercial de lucrar com a compra e venda de mercadorias entre o oriente e o ocidente. (BRITTO FILHO, 2011). O comércio 
também foi responsável pela aproximação dos povos, mas também desencadeou guerras. Os portugueses, como grandes comerciantes que eram, depararam-se com a Ilha de Vera Cruz, posteriormente denominada de Brasil, onde encontraram enorme variedade de temperos, condimentos e demais matérias primas que os colocaram como os principais comerciantes da Europa, ao longo de certo tempo. A exemplo de Portugal, outras nações também tiveram o seu momento de glória proporcionado pelo espírito mercantil. (SAES; SAES, 2013, p. 67 - 73)

O Brasil, enquanto colônia de Portugal, passou séculos apenas como produtor de matéria-prima para os povos europeus, nomeadamente os portugueses, tendo desenvolvido sua economia apenas após a sua independência em relação ao seu colonizador. Todavia, o desenvolvimento da economia brasileira não se deu da forma rápida. Com a declaração da independência do Brasil e o início do Brasil Império, a vida de quem aqui vivia foi impactada de forma brusca e o povo brasileiro, que antes dependia de Portugal para quase tudo, teve de se adaptar aos novos tempos. A cana-de-açúcar, primeiro, e depois, o café, eram os principais produtos de exportação desse período, porém, com o fim da escravidão e o enfraquecimento do coronelismo, esses produtos entraram em decadência, o que foi remediado por "estímulos artificiais", nas palavras de Celso Furtado (2005, p. 198). $\mathrm{Na}$ década de 1920, as exportações se encontravam estabilizadas, após reiteradas intervenções estatais na economia no sentido de estimular o plantio e a produção de café. De repente, ocorre a quebra da Bolsa de Valores de Nova York, em 1929.

O mundo inteiro sente os efeitos da crise. A década de 1930 se inicia de maneira nebulosa para a economia brasileira, notadamente pelo fato de o país estar calcado em um modelo monocultor cafeeiro, e alguns resquícios ainda da cultura da cana. Getúlio Vargas chega ao poder e propõe mudanças drásticas na economia como o fim da "Política do Café com Leite", então dominada pelos Estados de São Paulo e Minas Gerais. Outra medida então adotada foi o estímulo à agricultura e à indústria têxtil que tomava forma no Brasil. (CELSO FURTADO, 2005, p. 208). 
Essas mudanças feitas por Vargas desagradaram algumas camadas da sociedade da época, e os representantes políticos desses setores começam, assim, a pressionar o Governo. Como resposta, é instaurado o "Estado Novo", no ano de 1937, golpe político instituído através de Getúlio Vargas, mediante aliança com o Alto Escalão do Exército Brasileiro. Em termos práticos, o Estado Novo deu continuidade ao fomento da indústria e da economia que, apesar de fragilizada com a Segunda Guerra Mundial - época em que a moeda brasileira encontrava-se desvalorizada -, ainda se mantinha de forma timidamente aquecida. (BRITTO FILHO, 1945).

Nesse período, a postura comercial brasileira era a de fomentar a própria economia. Exemplo dessa estratégia desenvolvimentista era o alinhamento do Brasil com as grandes potências capitalistas da época, em especial os Estados Unidos da América. Com esse alinhamento comercial, passou o Brasil também a apoiar, no período de guerra, os países aliados aos ianques. Os investimentos estadunidenses não tardaram em chegar e a economia local é impulsionada. Importantes instituições são criadas, a exemplo da Companhia Siderúrgica Nacional, em 1941, localizada na Cidade de Volta Redonda, Rio de Janeiro. (BARROS, 2015)

Com o fim da Segunda Grande Guerra, enquanto vários países, principalmente os europeus, tentavam se restabelecer, a economia brasileira continuava a se expandir e a receber estímulos. A intervenção do Estado na economia aumentou ainda mais e foram criadas várias empresas estatais, que visavam atender a indústria de base, como, por exemplo, a Companhia Vale do Rio Doce e a Eletrobrás. Sobre esse período do Governo Vargas, Pedro Paulo Zahluth Bastos (2006, p. 244) afirma que o modelo de Estado intervencionista foi marcante, sobressaindo-se a política de atração de investimentos externos, principalmente dos Estados Unidos da América e de empresas internacionais privadas. Com essa política, intentava o referido governo se utilizar desses investimentos com o objetivo de "superar estrangulamentos estruturais ao desenvolvimento no final do processo". 
Essa postura interventiva adotada na Era Vargas iria então refletir diretamente nos próximos Governos, em especial nos dos militares. Esses governos, inobstante diminuição das liberdades e coerção de determinados grupos, que estavam a atentar contra o status quo por meio de atentados terroristas, assaltos a bancos e carros forte, e sequestros, como os dos embaixadores norte-americano Charles Burke Elbrik e alemão Ehrenfried von Holleben (ZINGANO; GOELZER, 2018), obtiveram êxito no campo econômico. O parque industrial iniciado na Era Vargas e fomentado pelos governos seguintes como o de Juscelino Kubitschek ${ }^{3}$ foi fortalecido pelos militares. (MARANHÃO, 1985). Foram criados ainda programas de viés econômico, como, por exemplo, o Plano de Ação Estratégica do Governo, que buscava equilibrar a inflação e a instabilidade do mercado à época. O intuito era estabilizar os preços, a inflação, o mercado e para isso foram realizadas e levantadas instituições que hoje regem o mercado interno, como o Banco Central e o Conselho Monetário Nacional. (NOGUEIRA, 1993, p. 266).

Foi nesse mesmo período que os militares, em termos de plano econômico, cuidaram de forma mais detida da moeda vigente, com vistas a fortalecê-la e a privilegiá-la. Era o Plano de Ação Integrada do Governo. Foi quando o Estado, por meio dos Ministros Roberto Campos (Planejamento) e Octávio Gouveia de Bulhões (Fazenda), assumiu o primeiro plano organizado na condução do cenário econômico brasileiro, que outrora ocorria de forma tímida. Em síntese, as ações se concentravam em combater a inflação, conjuntamente com medidas que visavam reformar estruturalmente a economia, como a reforma tributária, a monetáriafinanceira e a política externa. (BELLINGIERI, 2019). Na área fiscal, os militares conseguiram regular a arrecadação e diminuíram de forma considerável o déficit

3 De acordo com Ricardo Maranhão (1985), Juscelino tinha verdadeira ambição em ver o Brasil industrializado e, para isso, criou o chamado "Plano de Metas", o qual, dentre outras coisas, expandiu o parque industrial local. Nesse mesmo movimento de revolução econômica foi também aquecido o sonho da nova capital, com seu famoso slogan "50 anos em 5", que culminou com a construção de Brasília, que foi a grande marca desse Governo. 
fiscal.

O referido Plano de Ação Integrada do Governo, por outro lado, também acabou por majorar impostos. Consequentemente, houve incremento da arrecadação, o que acabou por propiciar equilíbrio inflacionário. Em adição, houve controle dos gastos e dos financiamentos públicos; incentivou-se as exportações através de incentivos fiscais e foram modernizados os órgãos públicos relacionados à exportação; estimulou-se outrossim o incremento dos investimentos estrangeiros com garantias a investidores e revogou-se uma lei do governo João Goulart que limitava a remessa de lucros ao exterior por parte de empresas estrangeiras que aqui atuavam. Por fim, o mercado de capitais foi aquecido, que era algo pouco explorado à época. (SIMONSEN; CAMPOS, 1976).

Todavia, o Plano de Ação Integrada do Governo não é marcado apenas como uma era de bonança para a economia brasileira. Apesar de se ter um maior controle inflacionário, e a atividade industrial se manter em aparente aquecimento, os índices de inflação ainda estavam em patamares considerados elevados. Adicione-se a isso o fato da correção monetária ter desencadeado um cenário de oscilação de preços, pois os índices eram reajustados "automaticamente". Para Rubens Penha Cysne (1993), essa equação: inflação alta mais oscilação de preços desembocava em insegurança mercadológica, o que afastava investidores e consequentemente deixava a economia estagnada. Essa estagnação econômica acabou então por desacelerar o parque industrial herdado do Governo Kubitschek, que vinha se desenvolvendo e crescendo relativamente bem.

\subsection{O “MILAGRE ECONÔMICO” BRASILEIRO}

Como mencionado acima, os primeiros anos de governo militar foram marcados, na seara econômica, pela implementação de programas de apoio à economia nacional da época, bem como por fomentos nos âmbitos fiscal e 
creditício. Em um primeiro momento, o Plano de Ação Integrada do Governo soergueu a economia brasileira, que vinha amargando elevados índices inflacionários, desde o final do Governo João Goulart. Em paralelo, houve uma reaproximação, por parte do Estado, da economia ${ }^{4}$ (FURTADO, 2005). O resultado dessas medidas foi que, do período de 1967 a 1973, o Brasil atingiu taxas de crescimento econômico favoráveis. Rubens Penha Cysne (1993) atribui o crescimento econômico brasileiro desse lapso temporal à adoção de políticas econômicas que buscavam driblar a flutuação inflacionária e ao mesmo tempo recuperar a indústria nacional $\mathrm{e}$, consequentemente, o mercado interno ${ }^{5}$. A conjuntura econômica mundial também influenciou a economia local.

Em resumo, o crescimento econômico do Brasil nesses seis anos foi resultado de investimentos estatais em certos setores da economia, o que resultou em fomento do setor privado. Outro fator que contribuiu para os números positivos da economia brasileira foi o incremento das exportações e uma maior atenção à geração de empregos $^{6}$. A equipe econômica de Delfim Netto conseguiu ainda identificar que grande parte do insucesso da contenção da inflação era a oscilação dos preços advinda do mercado de crédito. Dessa forma, buscou compatibilizar o mercado de crédito com o controle direto no aumento de preços. (VELOSO et al, 2008).

$\mathrm{O}$ resultado desse conjunto de medidas foi que o PIB brasileiro, a partir de 1967, saltou para dois dígitos e os índices inflacionários ficaram entre 16\% e 27\%, algo que não ocorria desde o início da década de 1960. (LAGO, 1990). O produto industrial sempre foi superior ao Produto Interno Bruto e com o boom econômico de 1967 a 1973 os números se inverteram e o PIB superou o produto industrial. O setor

\footnotetext{
${ }^{4}$ Essa aproximação, em verdade, começou no governo de Getúlio Vargas, quando foram criadas diversas empresas estatais, a fim de fortalecer o parque industrial nacional. A intenção de Vargas era criar uma ambiência onde se pudesse produzir riquezas e, com isso, o Brasil pudesse se inserir no centro econômico mundial como fornecedor de bens manufaturados. (CYSNE, 1993).

${ }^{5}$ Cita-se o saneamento das contas públicas como fator que contribuiu para os números positivos da economia brasileira da época. (MACARINI, 2000).

${ }^{6}$ Cumpre ainda registrar que, após a adoção das medidas acima citadas, alguns setores da economia foram atingidos de modo positivo como agricultura e habitação. (MACARINI, 2000).
} 
industrial, nomeadamente, o de transformação cresceu aceleradamente, reduzindo a ociosidade desse segmento, a qual caiu, de 24\%, em 1967, para 7\%, em 1971. (BONELLI; MALAN, 1976).

Com relação ao setor fiscal, a política de fomento do crédito e os incentivos fiscais propiciaram um outro boom, dessa vez no mercado de ações. No entanto, essa "explosão" foi diretamente impactada pela crise das bolsas de 1971, no âmbito do mercado internacional. Essa crise frustrou os planos da equipe econômica de Delfim Netto, que visava criar uma base sólida para o setor creditício, a fim de que pudesse baratear e facilitar o crédito para empresas nacionais. (WELLS, 1973).

Como se pode ver, o "milagre econômico" elevou a economia brasileira. As dificuldades enfrentadas pela equipe econômica da época foram enormes, mas as políticas adotadas foram certeiras. Malgrado essas políticas terem viés intervencionista, há de se concluir que a equipe econômica da época criou as bases para que políticas menos intervencionistas fossem posteriormente adotadas. Nesse vértice, observar-se-á que o legado econômico deixado pelos militares refletiria diretamente nos governos civis pós-1985, como se verá a seguir.

\section{DA VIGENTE ORDEM ECONÔMICA CONSTITUCIONAL: INFLUÊNCIAS E PRINCÍPIOS}

Inicialmente, convém esclarecer que as ordens econômica e jurídica são distintas, todavia, em âmbito constitucional, acabam por se fundir e originar a Ordem Jurídica Econômica. A expressão "Ordem Econômica” é produto da ordem contemporânea mundial, a qual passou a ser utilizada especialmente pelas Constituições do Pós-Primeira Guerra Mundial, a exemplo da Constituição Alemã de Weimar. É perceptível, na Europa, a transição do modelo anterior (Pré-Primeira Guerra), em que o Estado seguia os moldes do "laissez faire, laissez passer", ou seja, um modelo de políticas liberais, que deixava o mercado seguir de forma livre e 
sem maiores intervenções, para o de bem-estar social, onde as políticas adotadas eram mais voltadas para o social, mas que transferia esse custo para a conta dos contribuintes.

Adota-se então o modelo de Estado-Intervencionista, o qual efetivamente passa a interferir nas relações privadas e deixa para trás o liberalismo de Adam Smith. É o início da era das Constituições Econômicas, como já mencionado. Nestas Constituições, a economia passa por um processo de normatização e ganha nuances jurídicas. Constitucionalizar a Economia, com a criação de princípios, garantia então ao Estado a validade de sua intervenção no seio econômico. Cumpre elucidar que foi a Constituição de Weimar quem primeiro admitiu a intervenção estatal na economia. Para Gilberto Bercovici (2004, p. 40 - 41), assuntos relacionados à política econômica no Estado Liberal são decididos pelo mercado. Por sua vez, no Welfare State, essas questões são deslocadas para o âmbito da gestão pública. Assim, verificam-se dois ordenamentos distintos nas chamadas constituições econômicas, quais sejam, um que regula as relações do Estado com o mercado e outro que versa acerca da organização dos mercados. Em ambos os casos, o Estado se impõe sobre a iniciativa privada.

\subsection{DIRETRIZES ECONÔMICAS DA CONSTITUIÇÃO FEDERAL DE 1988}

Como explanado acima, a Constituição da República Federativa do Brasil foi influenciada pelo Estado-Social instaurado na Europa, após a $1^{\text {a }}$ Grande Guerra. Esse Diploma não é simplesmente um conjunto de normas superiores constante do Ordenamento Jurídico brasileiro. Trata-se de verdadeiro marco no tocante a direitos e garantias fundamentais, em especial liberdade, igualdade e dignidade da pessoa humana. Por outro lado, esse agrupamento de direitos e garantias se encontra harmonizado com a livre iniciativa e com a dignidade e valorização do trabalho 
humano, de acordo com o art. 170 da CRFB/887 . Com efeito, é perceptível que o texto constitucional não adota primados exclusivos do welfare state, pelo contrário, é notória a adoção de postulados do liberalismo, em especial quando assegura a todos "o livre exercício de qualquer atividade econômica, independentemente de autorização de órgãos públicos". (CRFB/88, § único do art. 170).

Celebrando a livre iniciativa como um de seus princípios norteadores, portanto, vê-se, de forma clara, que a Constituição brasileira adotou o sistema capitalista (SAYEG, 2019). Nessa senda de raciocínio, essa livre iniciativa impõe a adoção de políticas que assegurem a economia de mercado. Este, por sua vez, exige, acima de tudo, liberdade ampla nos meios empresarial e contratual. Para Eros Roberto Grau (2004, p. 186 - 187), a liberdade de iniciativa abrange todas as formas de produção individuais e/ou coletivas, dando ensejo às iniciativas privada, cooperativa, autogestionária e pública.

Desta feita, seja no âmbito empresarial, no tocante à concessão de maior liberdade de atuação e permitindo o crescimento corporativo ${ }^{8}$, albergando o pequeno produtor, as cooperativas e as demais formas de produção individuais, coletivas, de grande porte ou de pequeno porte, a iniciativa privada é parâmetro norteador da economia brasileira. O Brasil, portanto, deve valorizar o capital e a geração de lucro, segundo à sua Lei Maior. Com relação à valorização do trabalho

7 Art. 170. A ordem econômica, fundada na valorização do trabalho humano e na livre iniciativa, tem por fim assegurar a todos existência digna, conforme os ditames da justiça social, observados os seguintes princípios:

I - soberania nacional; II - propriedade privada; III - função social da propriedade; IV - livre concorrência; V - defesa do consumidor; VI - defesa do meio ambiente, inclusive mediante tratamento diferenciado conforme o impacto ambiental dos produtos e serviços e de seus processos de elaboração e prestação; VII - redução das desigualdades regionais e sociais; VIII - busca do pleno emprego; IX - tratamento favorecido para as empresas de pequeno porte constituídas sob as leis brasileiras e que tenham sua sede e administração no País.

Parágrafo único. É assegurado a todos o livre exercício de qualquer atividade econômica, independentemente de autorização de órgãos públicos, salvo nos casos previstos em lei.

${ }^{8}$ Roberto Simonsen e Eugênio Gudin (2010, p. 16) defendem que o Estado deve se restringir a "cooperar com a Iniciativa Privada, através de medidas legislativas e administrativas, que permitam e facilitem a livre expansão de seus empreendimentos." 
humano e à dignidade da pessoa humana, não se vê ponto de choque com o capitalismo. Em reverso, a intenção da Lei das Leis é propiciar ambiência de crescimento econômico para que a iniciativa privada possa prover empregos e renda, isto sim, trata-se de verdadeira política social. Quando se tem emprego, temse dignidade, logo, está-se respeitando o artigo $1^{09}$, III da Constituição ${ }^{10}$.

Nesse sentido, estimular o mercado, sem interferir na sua organicidade, é criar condições para que o povo tenha acesso ao emprego. Tendo acesso ao emprego, esse povo passa a ter dignidade. Desta feita, a valorização do trabalho humano passa por um mercado pujante, que propicie crescimento ao empreendedor. Se esse empreendedor se sente estimulado a investir, e se ele consegue expandir os seus negócios, há geração de postos de trabalho. Havendo postos de trabalho, efetiva-se justiça social. Todavia, há quem defenda uma intervenção mais direta do Estado na economia, como na redistribuição de renda. Eros Roberto Grau (2004, p. 208), por exemplo, afirma que "justiça social, inicialmente, quer significar superação das injustiças na repartição, a nível pessoal, do produto econômico (...) passando a consubstanciar exigência de qualquer política econômica capitalista".

Essa interferência estatal no mercado no sentido de se repartir riquezas, sob o argumento da justiça social é delicada. Se, por um lado, gera-se artificialmente distribuição de renda, por outro, esse tipo de política pode desestimular o empreendedorismo e inclusive gerar fuga de capitais para países que respeitam mais a liberdade e a propriedade privada. Portanto, as ideias de igualdade, fraternidade, paz e justiça social devem ser equalizadas com a liberdade econômica, ao invés de serem contrapostas entre si, sob pena do mercado se retrair e não mais ser capaz de

9 Art. $1^{\text {o }}$ A República Federativa do Brasil, formada pela união indissolúvel dos Estados e Municípios e do Distrito Federal, constitui-se em Estado Democrático de Direito e tem como fundamentos:

[...] III - a dignidade da pessoa humana; [...]

${ }^{10}$ Cumpre destacar as palavras de Donald J. Boudreaux (2017, p. 48 - 52), para quem a liberdade é um dos direitos mais sublimes do ser humano. "Pessoas sem liberdade, por conseguinte, possuem menos alterativas e habilidades do que pessoas livres para ir atrás e pôr em prática tais conhecimentos locais e detalhados." 
abrigar todos que necessitam de emprego para sobreviver. Em suma, quanto maior é a intervenção estatal na economia, mais o Estado gera empecilho para a criação de riqueza. (WAPSHOTT, 2016, p. 341).

\subsection{DOS DEMAIS PRINCÍPIOS REGENTES DA ECONOMIA BRASILEIRA À LUZ DO TEXTO CONSTITUCIONAL}

O primeiro princípio, o qual o legislador constitucional preocupou-se em trazer à Constituição, no que tange à economia, foi o da soberania nacional, que não somente servirá de regente econômico para o mercado brasileiro, mas que é elemento basilar da República Federativa do Brasil, de acordo com o art. $1^{\circ}$ da CRFB/88. Falar de soberania em contexto econômico, neste caso, significa adotarse um sistema capitalista nacional autônomo. Ao longo de todo o texto constitucional, resta evidenciado o cuidado em proteger a soberania do Brasil em detrimento de entidades de direito púbico e privado alienígenas. Essa característica não é apenas da atual Constituição, mas acompanha as leis mães do país desde a proclamação da República.

O capitalismo autônomo em foco, contudo, não se contrapõe à abertura do mercado brasileiro ao mercado mundial. A comunicação com o mercado externo, que já vinha sendo implementada pelos militares, foi reforçada pela Constituição Federal de 1988. Em termos constitucionais, a ideia de soberania está ligada à autonomia, mas não de fechamento ou ruptura com os demais mercados. Um Estado soberano é aquele concebido como detentor de um ordenamento jurídico de essência superior; nele, o poder estatal se encontra em patamar mais elevado se comparado com os demais poderes sociais; ser soberano significa ter governo próprio, reconhecido e respeitado; é ter independência em relação a qualquer outra corporação, Estado ou potência mundial; é ter poder de imperium sobre dado território, povo e demais poderes sociais, sem, contudo, comprometer o direito à 
vida, à liberdade e à propriedade. Por fim, esse poder de império do Estado Soberano deve permitir que o mercado seja capaz de se autogerir.

$\mathrm{O}$ segundo princípio diz respeito ao direito à propriedade privada. Nesse sentido, a Constituição vigente pondera propriedade privada com função social da propriedade, de modo que a primeira não é absoluta. O Estado permite então o exercício do direito de possuir propriedade privada, porém o condiciona à forma como esse direito será exercido. Na visão de governos anteriores, cumpre registrar, a função social da propriedade se sobrepunha ao direito de propriedade, pois era clarividente o estímulo e até suporte financeiro a determinados movimentos sociais que invadiam, saqueavam e destruíam a propriedade privada ${ }^{11}$.

O terceiro princípio diz respeito à livre concorrência, o qual é essencial para um mercado sadio. Esse princípio deve dar suporte à livre circulação de riquezas e à autonomia empresarial. No tocante à qualidade dos produtos disponibilizados no mercado, interessante registrar que a livre concorrência faz com que apenas os melhores produtos permaneçam sendo negociados. Essa instabilidade concorrencial impõe ao ofertante que fique vigilante na constante melhora de seu produto. Nesse sentido, ter diversas opções dentro de uma concorrência praticável gera ao consumidor liberdade de escolha, e essa liberdade somente pode ser garantida pela livre concorrência. Esta livre concorrência, por sua vez, garante a seleção dos melhores produtos para a sociedade.

O quarto princípio é a proteção do consumidor. Esse princípio enxerga o consumidor como a parte mais frágil dentro do mercado concorrencial e, ao mesmo tempo, hipossuficiente em relação aos componentes do mercado. Como dito acima, a livre concorrência permite pluralidade de escolhas por parte do consumidor em

\footnotetext{
${ }^{11}$ Eis alguns exemplos: MST destrói 15 anos de pesquisa em biotecnologia. (VEJA, 2016, s/p); Grupo do MST destrói laboratórios da Universidade Federal de Alagoas. (G1, 2013, s/p); MST invade laboratório e destrói pesquisas de vinte anos no RS. (DGBC, 2019, s/p); Minas é condenada a indenizar fazendeiro por invasão do MST. (ESTADÃO, 2006, s/p); MST invade de novo área da Monsanto com transgênicos. (REBELION, 2019, s/p).
} 
um cenário de mercado diversificado. Agora, há de se ter bastante cuidado quando se intervém nessa relação - consumidor-ofertante, com vistas a não causar abalos no mercado. Se essa intervenção for desmoderada poderá levar o ofertante à falência. Contudo, se a relação for de coordenação, a ambiência concorrencial será extremamente benéfica para o desenvolvimento econômico de um país.

Os princípios relativos à defesa do meio ambiente, redução das desigualdades regionais e sociais, e busca do pleno emprego visam minimizar os impactos das diferenças regionais e sociais. Mais uma vez, hão de ser observados em cotejo com a mínima intervenção, com vistas a conturbar o mínimo possível as relações mercadológicas. Por fim, mas não menos importante, o princípio do tratamento favorecido para as microempresas e empresas de pequeno porte. Mais uma vez, toda e qualquer política pública deve ter o cuidado para não desarmonizar o mercado concorrencial. Uma vantagem exagerada por parte do Estado em um dado segmento empresarial poderá desembocar na quebra de outro.

Assim, deve-se dosar a medida para que não haja violação ao princípio da livre concorrência. O cerne da questão é a não concessão de privilégios, mas efetivar o princípio da isonomia, a fim de garantir que os menores possam concorrer com os maiores. Desse modo, assistir microempresas e/ou empresas de pequeno porte significa propiciar concorrência ótima para aqueles que possuem menos poder de competitividade. São esses, pois, os principais princípios constantes no texto constitucional brasileiro. A seguir, analisar-se-á se o Estado brasileiro tem adotado postura intervencionista ou liberal junto ao mercado.

\section{BRASIL: ESTADO LIBERAL OU INTERVENCIONISTA}

Consoante visto acima, a CRFB/88 foi influenciada pelo modelo de bemestar social europeu (modelo keynesiano). Nesse sentido, esse Diploma assegura uma série de benesses nas áreas da saúde e da educação, bem como dos serviços 
assistenciais públicos, os quais albergam renda, habitação e previdência social. Esse modelo político-econômico também prevê intervenção direta na economia, de modo que o Estado passa a regulamentar praticamente toda a cadeia produtiva, sendo ele o principal agente de geração de riquezas. O ponto negativo desse sistema é o agigantamento da máquina estatal e, consequentemente, dos gastos públicos, os quais, em regra, tendem a suplantar a capacidade arrecadatória da iniciativa privada. Quando se fala em "agigantamento" do Estado, está-se referindo não apenas à classe política, mas a todo um corpo de pessoas e instituições que tiram proveito das facilidades, dos privilégios e das burocracias inerentes à máquina pública. São os lobistas, os burocratas, os grupos de interesses, que oneram os custos estatais. Portanto, quanto maior o Estado, mais cara é a sua manutenção.

A CRFB/88 é fruto da conjunção do social com o liberal. Se, de um lado, o Estado atua para reduzir desigualdades econômicas, por outro, ele deve preservar a livre iniciativa. De outro modo, quando o Estado desapropria, atende ele ao princípio da função social da propriedade. Contudo, esse ato político-jurídico não pode colidir com o sagrado direito de propriedade. As tensões sempre existirão, cumprindo aos agentes políticos e ao Poder Judiciário atuar no sentido de suavizálas. O importante é que o Estado se restrinja ao papel de garantidor de uma ambiência de liberdade, onde o empreendedor que queira começar um negócio não tenha que se preocupar com a burocracia, com os altos custos, com a cobrança de "taxas" absurdas e com a corrupção de determinados agentes públicos, que usualmente se utilizam de subterfúgios para extorquir quem empreende.

No tocante à intervenção do Estado brasileiro na economia, verificam-se duas modalidades, a direta e a indireta. A intervenção direta pode ser exemplificada quando o Estado exerce monopólio sobre determinado setor, como é o caso do petróleo e demais minérios (art. 177 da CRFB/88). Outro exemplo é a exclusividade em garantir a segurança pública, observando-se o interesse coletivo (art. 173 da CRFB/88). Na intervenção indireta, por sua vez, o Estado controla a economia 
majoritariamente através do ordenamento jurídico infraconstitucional, espelhado, naturalmente, nos princípios constitucionais outrora abordados, dentre outros que não foram objeto de estudo nesse trabalho.

São muitas as leis que tratam da economia e que a regulam, criando através de órgãos diversos verdadeiros controladores dos agentes econômicos no âmbito do mercado interno brasileiro (art. 174 da CRFB/88). Dessa forma, falar da atuação indireta do Estado no domínio econômico seria verificar, a partir de autarquias, de empresas públicas etc., como o mercado e a concorrência se comportam, e, a partir dessa análise, criar regulamentos para disciplinar a relação. Já a atuação estatal direta seria a forma mais pura de intervenção estatal, uma vez que ocorre quando o próprio Estado atua como agente econômico, que é o que ocorre a exemplo do monopólio do petróleo no Brasil.

Essas formas de regulação visariam evitar monopólios ou oligopólios, concorrência desleal, imoderação de preços e lucros. Para Paula Forgioni (2010, p. 39), a intervenção estatal na economia é de grande valia para a implementação de políticas sociais e condução do sistema. Salomão Filho (2001), por sua vez, diferencia regulação de concorrência. Para ele, regulação trataria da atuação mais direta do Estado, enquanto que a concorrência seria uma forma de atuação indireta, através, por exemplo, de órgãos como as agências reguladoras, o Conselho Administrativo de Defesa Econômica - CADE, o Banco Central, a Agência Nacional de Telecomunicações - ANATEL, a Agência Nacional de Aviação Civil ANAC, a Agência Nacional de Energia Elétrica - ANEEL, a Agência Nacional de Transportes Terrestres - ANTT, a Agência Nacional de Saúde - ANS e Agência Nacional de Petróleo - ANP.

Sabe-se que um dos grandes males de uma economia saudável advém de uma falsa concorrência praticável, pois isto desequilibra o mercado e seu fluxo em linhas gerais, além de ferir o Direito Econômico e a própria Constituição, que tão bem definem os parâmetros a serem seguidos para minar os problemas estruturais 
decorrentes de uma concorrência desleal. A intervenção estatal direta ou indireta deve ser muito bem sopesada, com vistas a evitar o engessamento econômico decorrente do erro na medida. É comum que um Estado inchado gere paralisia dos agentes privados, congestionando o fluxo econômico. Há quem diga inclusive que as políticas públicas do Brasil dos últimos anos não tiveram cunho intervencionista, mas regulador. (SCHMITT, 2006). Interventor ou regulador, se o Brasil pretende se inserir no conjunto de países que mais geram riquezas no planeta deverá, além de dosar a medida da intervenção ou da regulação do mercado, diminuir a burocracia e a carga tributária incidente sobre a atividade empresarial.

Por fim, cumpre fazer alusão à Medida Provisória nº 881, de 30 de abril de 2019, recém-publicada quando da elaboração desse trabalho. A ementa do Diploma "Institui a Declaração de Direitos de Liberdade Econômica, estabelece garantias de livre mercado, análise de impacto regulatório, e dá outras providências." A justificativa desse regramento diz respeito à urgente necessidade de evidenciar que o Estado Brasileiro não precisa autorizar o empreendedor para que ele exerça sua atividade econômica, ou seja, para empreender, prescinde-se de permissão prévia do Estado. Outrossim, objetiva o atual governo assegurar segurança ao particular para que ele possa produzir renda e gerar postos de trabalho. Essa medida provisória possui contornos liberais, pois eleva a liberdade econômica a patamar de destaque no que tange ao desenvolvimento do Brasil, o qual se encontra atualmente com número elevado de desempregados e mergulhado em crise econômica. Nesse sentido, digna de encômio essa iniciativa do Estado brasileiro de associar a liberdade econômica com o progresso. Sabe-se que, quanto maior a intervenção do Estado na economia, mais desestimulado se sente o empreendedor, no sentido de arriscar o seu capital em negócio que, devido à conjuntura, tem grande probabilidade de dar errado. Assim, quanto mais liberdade, mais se estimula o empreendedorismo e o desenvolvimento econômico é consequência lógica desse processo. 


\section{CONSIDERAÇÕES FINAIS}

Diante de todo o exposto, verificou-se que o estudo analisou a economia brasileira do período colonial, onde o Brasil era um grande exportador de matériaprima, até o momento em que se concentrou na produção de cana-de-açúcar e café. Com a quebra da bolsa de Nova Iorque, em 1929, os produtores brasileiros amargam prejuízos financeiros de grande monta e a economia nacional passou por profunda transformação, quando Getúlio Vargas passa a estimular a agricultura e a indústria têxtil que tomava forma no Brasil. Vê-se ainda o alinhamento do Brasil com as grandes potências capitalistas da época, em especial com os Estados Unidos da América. Os investimentos estadunidenses aportam por aqui e são um dos fatores de alavancamento da economia local. Importantes instituições são criadas, a exemplo da Companhia Siderúrgica Nacional, em 1941, localizada na Cidade de Volta Redonda, Rio de Janeiro.

Com o fim da Segunda Grande Guerra, a intervenção do Brasil na economia aumenta e criam-se várias empresas estatais, que visavam atender à indústria de base, como, por exemplo, a Companhia Vale do Rio Doce e a Eletrobrás. Essa postura interventiva adotada na Era Vargas iria então refletir diretamente nos próximos Governos, em especial nos dos militares. Nessa nova fase da História brasileira, o parque industrial iniciado na Era Vargas é fortalecido. É criado o Plano de Ação Estratégica do Governo, que buscava equilibrar a inflação e a instabilidade do mercado à época. O intuito era estabilizar os preços, a inflação, o mercado e para isso foram realizadas e levantadas instituições que hoje regem o mercado interno, como o Banco Central e o Conselho Monetário Nacional.

Sobressaem-se, na era dos militares, as figuras de Roberto Campos, Ministro do Planejamento, e Octávio Gouveia de Bulhões, Ministro da Fazenda. É criado o Plano de Ação Integrada do Governo, considerado o primeiro plano organizado 
voltado à condução da economia. Dentre as ações, destacam-se o combate à inflação, conjuntamente com medidas que visavam reformar estruturalmente a economia, como a reforma tributária, a monetária-financeira e a política externa. $\mathrm{Na}$ área fiscal, os militares conseguem regular a arrecadação e diminuir de forma considerável o déficit fiscal. Por outro lado, houve majoração de impostos. Consequentemente, a receita aumentou, o que acabou por propiciar equilíbrio inflacionário.

Em adição, houve controle dos gastos e dos financiamentos públicos; incentivou-se as exportações através de incentivos fiscais e os órgãos públicos relacionados à exportação foram modernizados; os investimentos estrangeiros foram incrementados com garantias a investidores e revogou-se uma lei do governo João Goulart que limitava a remessa de lucros ao exterior por parte de empresas estrangeiras que aqui atuavam. Por fim, estimulou-se ainda o mercado de capitais, que era algo pouco explorado à época. Com essas medidas, o governo militar elevou o Brasil à qualidade de potência econômica mundial, fase essa denominada de milagre econômico.

Em relação ao cerne desse trabalho, o que se buscou foi demonstrar que na historiografia da economia brasileira, os gestores públicos sempre adotaram postura intervencionista de mercado. Mesmo quando o sistema liberal era o predominante na Europa, e apesar das constituições brasileiras trazerem princípios liberais em seu texto, o Brasil sempre foi um país intervencionista. Quando o Estado de bem-estar social suplantou o liberalismo na Europa, o Brasil, além de intervencionista, passou a adotar políticas mais voltadas ao social. O ápice do keynesianismo nessas plagas foi a Constituição da República de 1988. Esse Diploma tratou de assegurar a todos saúde e educação, bem como os serviços assistenciais públicos, os quais albergam renda, habitação e previdência social.

O ponto negativo desse sistema é o agigantamento da máquina estatal e, consequentemente, dos gastos públicos, os quais, em regra, tendem a suplantar a 
capacidade arrecadatória da iniciativa privada. Os gastos públicos aumentam na proporção que o Estado ingressa em vias que são percorridas pela iniciativa privada. Em um Estado inchado, custa muito para a sociedade ter de bancar a classe política, além de todo um corpo de pessoas e instituições que tiram proveito das facilidades, dos privilégios e das burocracias inerentes à máquina pública, tais como: lobistas, burocratas, grupos de interesses etc. Assim, quanto maior o Estado, mais cara é a sua manutenção.

Muito embora a CRFB/88 seja fruto da conjunção do social com o liberal, há seguramente uma preponderância de políticas intervencionistas em detrimento de políticas que se restrinjam ao papel de garantidor de uma ambiência de liberdade, onde o empreendedor que queira começar um negócio não tenha que se preocupar com a burocracia, com os altos custos, com a cobrança de "taxas" absurdas e com a corrupção de determinados agentes políticos e públicos, que usualmente se utilizam de subterfúgios para extorquir quem empreende.

Políticas intervencionistas desequilibram o mercado e engessam a economia. Com efeito, quanto mais há interferência estatal na organicidade do mercado, mais se gera paralisia dos agentes privados, o que congestiona o fluxo econômico. Interventor ou regulador, se o Brasil pretende se inserir no conjunto de países que mais geram riquezas no planeta deverá, além de dosar a medida da intervenção ou da regulação do mercado, diminuir a burocracia e a carga tributária incidente sobre a atividade empresarial, assegurando o livre exercício da atividade econômica, consoante determinado no texto constitucional.

Por fim, espera-se que, com a publicação da Medida Provisória nº 881, de 30 de abril de 2019, o particular se sinta mais seguro para empreender. Se isso ocorrer, a decorrência lógica é que sejam gerados postos de trabalho e renda, reaquecendo a economia que já há alguns anos amarga números negativos. Mais liberdade econômica significa desenvolvimento econômico. Assim, espera-se que o atual governo cumpra a promessa de campanha no sentido de diminuir o tamanho do 
Estado (consequentemente dos gastos públicos) e essa medida possa refletir em confiança por parte de investidores nacionais e estrangeiros, no sentido de aportar capital por essas plagas e com isso movimentar a combalida economia.

\section{REFERÊNCIAS BIBLIOGRÁFICAS}

ABREU, Hugo. O outro lado do poder. Rio de Janeiro: Nova Fronteira, 1979.

ARAÚJO, Lorena de Fátima Sousa. Princípios que regem a ordem econômica na Constituição Federal de 1988. Disponível em $<$ http://conteudojuridico.com.br/artigo,principios-que-regem-a-ordemeconomicana-constituicao-federal-de-1988,55484.html\#_ftn7>. Acesso em 04 mar. 2019.

BARROS, Gustavo. O desenvolvimento do setor siderúrgico brasileiro entre 1900 e 1940: Crescimento e substituição de importações. Estud. Econ., São Paulo, v. 45, n. 1, p. $153 \quad$ - 183, Mar. $2015 . \quad$ Disponível em: $<$ http://www.scielo.br/scielo.php?script=sci_arttext\&pid=S010141612015000100153\&lng=en\&nrm=iso>. Acesso em: 07 mai. 2019.

BASTOS, Pedro Paulo Zahluth. A Construção do Nacional Desenvolvimentismo de Getúlio Vargas e a Dinâmica de Interação entre Estado e Mercado nos Setores de Base. Revista Economia, Selecta, Brasília (DF), v.7, n.4, p. 239-275, dezembro 2006.

BELLINGIERI, Julio Cesar. A economia no período militar. (1964 - 1984): crescimento com endividamento. Disponível em:< http://www.unifafibe.com.br/revistasonline/arquivos/hispecielemaonline/sumario/9/ 16042010171928.pdf>. Acesso em: 26 abr. 2019.

BERCOVICI, Gilberto. Constituição e estado de exceção permanente: atualidade de Weimar. Rio de Janeiro: Azougue, 2004.

BOUDREAUX, Donald J. Menos Estado e mais liberdade. Barueri: Faro Editorial, 2017.

BRASIL. Constituição (1988). Constituição da República Federativa do Brasil. Brasília, DF, Senado, 1998.

BRASIL. Decreto $n^{\circ}$ 53.670. Dispõe e aprova o Regimento Interno do Conselho 
Administrativo de Defesa Econômica. Brasília, 10 de março de 1964. Disponível

em: <http://www.planalto.gov.br/ccivil_03/decreto/Antigos/D53670.htm >. Acesso em 25 mar. 2019.

BRASIL. Lei no 12.529. Estrutura o Sistema Brasileiro de Defesa da Concorrência; dispõe sobre a prevenção e repressão às infrações contra a ordem econômica. Brasília, 02 de dezembro de 2011. Disponível em: <http://www.planalto.gov.br/ccivil_03/_ato2011-2014/2011/Lei/L12529.htm>. Acesso em 25 mar. 2019.

BRASIL, Medida Provisória $\mathbf{n}^{\mathbf{0}}$ 881. Institui a Declaração de Direitos de Liberdade Econômica, estabelece garantias de livre mercado, análise de impacto regulatório, e dá outras providências. Brasília, 30 de abril de 2019. Disponível em:< https://www.congressonacional.leg.br/materias/medidas-provisorias//mpv/136531>. Acesso em: 08 mai. 2019.

BRITTO FILHO, W. J. O princípio da não-discriminação tributária no comércio internacional de bens. Tese (Doutorado em Direito Econômico e Financeiro) - Faculdade de Direito da Universidade de São Paulo, São Paulo, 2011, 620 f. Disponível em:< http://www.teses.usp.br/teses/disponiveis/2/2133/tde28052012-154447/publico/Washington_Juarez_de_Brito_Filho_DO.pdf > Acesso em 26 abr. 2019.

CYSNE, RUBENS PENHA. Economia Brasileira no Período Militar. Est. Econ. São Paulo. 1993.

FALCON, Francisco J. C. Mercantilismo e Transição. Coleção Tudo é História. São Paulo: Editora brasiliense, 1985.

FORGIONI, Paula Andrea. Os fundamentos do Antitruste. $4^{\mathrm{a}}$ ed. ver. atual. e ampl. São Paulo: Revista dos Tribunais, 2010.

FRANCO FILHO, Alberto de Magalhães. Breve análise da Ordem Econômica Constitucional brasileira. In: Âmbito Jurídico, Rio Grande, XII, n. 70, nov. 2009. Disponível em: <http://www.ambitojuridico.com.br/site/index.php?n_link=revista_artigos_leitura\&artigo_id=6649>. Acesso em 26 abr. 2019.

FURTADO, Celso. O Capitalismo Global. São Paulo: Paz e Terra, 1998.

FURTADO, Celso. Formação Econômica do Brasil. 32. ed., São Paulo: 
Companhia Editora Nacional, 2005.

GRAU, Eros Roberto. A ordem econômica na Constituição de 1988 (interpretação e crítica). 9. ed., rev. e atual. São Paulo: Malheiros, 2004.

LAGO, Luiz Antonio Correa do. A retomada do crescimento e as distorções do milagre: 1967-1973. In: ABREU, Marcelo de Paiva (Org.). A ordem do progresso: cem anos de política econômica republicana, 1889 - 1989. Rio de Janeiro: Campus, 1990. p. $233-294$.

LEAL, Rogério Gesta. Impactos econômicos e sociais das decisões judiciais: aspectos introdutórios. Brasília: ENFAM, 2010.

MACARINI, José Pedro. A Política Econômica da Ditadura Militar no Limiar do "Milagre" Brasileiro: 1967/69. Disponível em:< http://www.eco.unicamp.br/docprod/downarq.php?id=1729\&tp=a>. Acesso em: 26 abr. 2019.

MACIEL, Ademar Ferreira et al. Estudos de Direito Constitucional: homenagem ao Prof. Ricardo Arnaldo Malheiros Fiuza. Belo Horizonte: Del Rey, 2009.

MARANHÃO, Ricardo. O Governo Juscelino Kubitscheck. 4. ed., São Paulo: Brasiliense, 1985.

MELLO, Celso Antônio Bandeira de Mello. Curso de Direito Administrativo. 31. ed. São Paulo: Malheiros, 2014.

NOGUEIRA, Dênio. Memória do Banco Central. Rio de Janeiro: Programa de História Oral do CPDOC/FGV, 1993.

PRADO JUNIOR, CAIO. História Econômica do Brasil. 42. ed., São Paulo: Editora Brasiliense, 1970.

SAES, Flávio Azevedo Marques; SAES, Alexandre Macchione. História econômica geral. São Paulo: Saraiva, 2013.

SALOMÃO FILHO, Calixto. Regulação da atividade econômica: princípios e fundamentos jurídicos. São Paulo: Malheiros, 2001.

SALOMÃO FILHO, Calixto. Direito concorrencial: as estruturas. 2. ed., São Paulo: Malheiros, 2002. 
SAYEG, Ricardo Hasson. O capitalismo humanista no brasil. Disponível em:< https://www.pucsp.br/capitalismohumanista/downloads/o_capitalismo_humanista_n o_brasil.pdf >. Acesso em: 07 jul. 2019.

SCHMITT, A.V. A exploração estatal da atividade econômica. Revista de Informação Legislativa, Brasília, v. 43, out/dez, 2006.

SIMONSEN, Mario Henrique; CAMPOS, Roberto de Oliveira. A nova economia brasileira. 2. ed. Rio de Janeiro: J. Olympio, 1976.

SIMONSEN, Roberto; GUDIN, Eugênio. A controvérsia do planejamento na economia brasileira. 3. ed. Brasília: Ipea, 2010. Disponível em:< http://www.ipea.gov.br/portal/images/stories/PDFs/livros/livro_simonsen_gudin_vo 103.pdf>. Acesso em: 07 mai. 2019.

VASCONCELLOS, Marco Antônio Sandoval de. Economia: micro e macro. São Paulo: Atlas, 2000.

VELOSO, Fernando A.; VILLELA, André; GIAMBIAGI, Fabio. Determinantes do "milagre" econômico brasileiro (1968-1973): uma análise empírica. Rev. Bras. Econ., Rio de Janeiro, v. 62, n. 2, p. 221-246, jun. 2008. Disponível em:<http://www.scielo.br/scielo.php?script=sci_arttext\&pid=S0034-

$71402008000200006 \& \operatorname{lng}=e n \& n r m=i s o>$. Acesso em 26 abr. 2019.

VILANOVA, Lourival. Causalidade e relação no direito. 4. ed. São Paulo: RT, 2000 .

WAPSHOTT, Nicholas. Keynes X Hayek: as origens e a herança do maior duelo econômico da história. Rio de Janeiro: Record, 2016.

WELLS, John. Euro-dólares, dívida externa e o milagre brasileiro. Estudos Cebrap, São Paulo, n. 6, p. 7-34, out./dez. 1973.

ZINGANO, Henrique; GOELZER, Mariana. Entre mitos e verdades: a história do regime militar. 3. ed. Porto Alegre: Brasil Paralelo, 2018.

Data da submissão: 11/06/2019

Data da primeira avaliação: 22/09/2019

Data da segunda avaliação: 15/07/2019

Data da aprovação: 15/07/2019 